\title{
APLICACIÓN DE LA OXIFERTIRRIGACIÓN PARA OPTIMIZAR LOS RECURSOS HÍDRICOS EN CÍTRICOS, BASADO EN LA APLICACIÓN DE PERÓXIDO DE HIDRÓGENO EN EL AGUA DE RIEGO
}

Robles García, J.M. (P)(1), Botía Ordaz, P. (1), Olivares Quilez, L. (1), Palazón López, J.A.(1), Navarro Acosta, J.M. (1), Arques Pardo, E.M. (1), Martínez Izquierdo, A.V. (1), Hernández Ballester F.M. (1), Pérez-Pérez, J.G. (1-2)

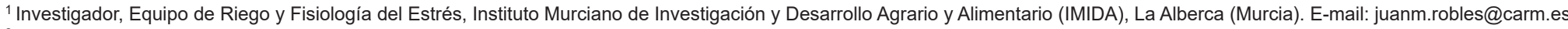

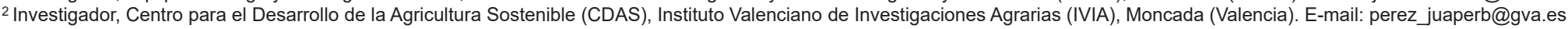

\section{Introducción} óptimo de $\mathrm{O}_{2}$ en la rizosfera

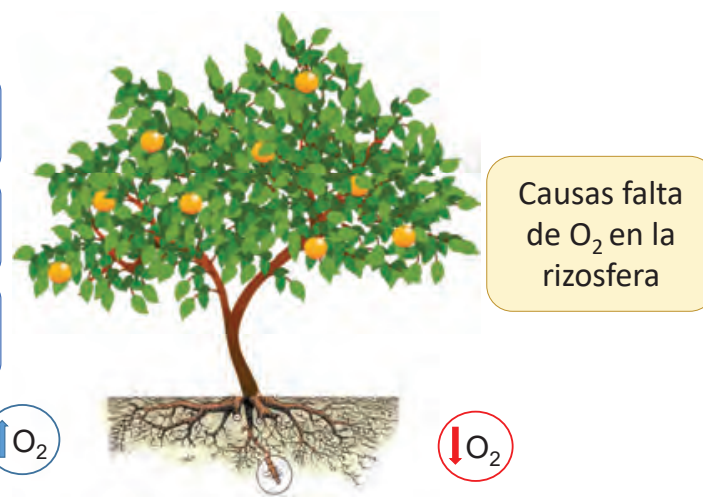

Favorece el crecimiento de la planta

Incremento del rendimiento
$y$ del cultivo

Mejora eficiencia uso del agua y fertilizantes

\section{Objetivo}

Evaluar la respuesta fisiológica y agronómica de la aplicación de la oxifertirrigación química, basada en la aplicación de peróxido de hidrógeno, como una herramienta auxiliar para aumentar el contenido de oxígeno a nivel radicular, en árboles adultos de mandarino

\section{Material y métodos}

\section{Material vegetal y Sistema de cultivo}

Árboles de mandarino híbrido var. 'Ortanique' sobre citrange 'Carrizo' en riego por goteo, con un sistema de mantenimiento del suelo de no laboreo Tratamientos

Control: $100 \%$ ETc $\left(0\right.$ ppm $\left.\mathrm{H}_{2} \mathrm{O}_{2}\right)$ OXI: $100 \%$ ETc (50-100 ppm $\left.\mathrm{H}_{2} \mathrm{O}_{2}\right)$

Medidas contenido $\mathrm{O}_{2}$

Determinación del contenido de $\mathrm{O}_{2}$ del agua de riego aplicada en el gotero con equipo portátil multifunción (HATCH mod. HQ 40d)

\section{Biometría de la planta} La tasa de crecimiento absoluto del tronco (AGR)
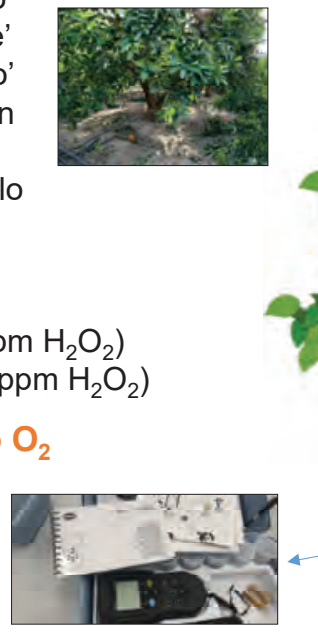
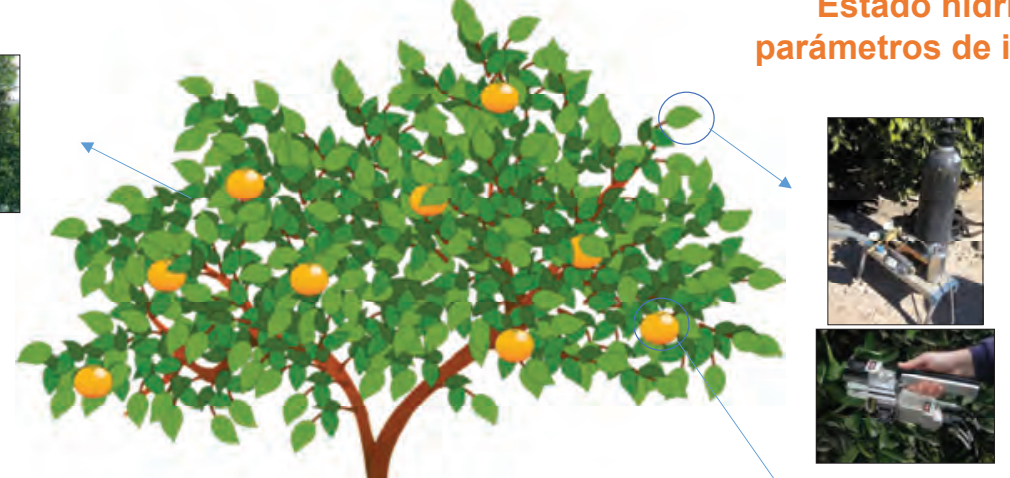

Compactación del suelo por no laboreo

Uso de aguas de baja calidad con elevada salinidad

Encharcamientos por exceso de riego o lluvias

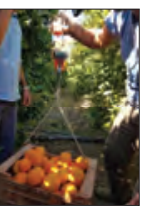

Contenido

mineral en hoja

Estado nutricional del cultivo, macroelementos (N, P, K, Ca y Mg) microelementos (Fe, $\mathrm{Cu}, \mathrm{Mn}, \mathrm{Zn}$ y $\mathrm{B}$ )
Estado hídrico de la planta y parámetros de intercambio gaseoso

El potencial hídrico de tallo al mediodía $\left(\Psi_{\text {tallo }}\right)$ se midió utilizando una cámara de presión (modelo 3000; Soil Moisture Equipment Corp.). Las medidas de intercambio gaseoso con un sistema portátil de fotosíntesis (Li-6400, Li-COR)

Producción

Se controló la producción ( $\mathrm{kg}$ árbol-1) número de frutos y peso medio del fruto de cada árbol. Se calculó la productividad del agua como la relación entre la cosecha y el agua de riego aplicada $\left(\mathrm{kg} \mathrm{m}^{-3}\right)$.

\section{Calidad del fruto}

Se evaluó: diámetro del fruto $(\mathrm{mm})$, Índice de color externo ( $\left(\mathrm{IC}_{\text {ext }}\right)$, espesor de corteza $(\mathrm{mm})$, porcentaje de zumo, corteza y pulpa, sólidos solubles totales (SST; ${ }^{\circ}$ Brix), acidez valorable (AT; $\mathrm{g} \mathrm{L}^{-1}$ ) e índice de madurez (IM)

\section{imi) ivia \\ 1.} d'Investigacions Agràries 